\title{
Comparing psychopathy traits and behavioral inhibition among smoker and non-smoker teenage students
}

Navazesh Marandizadehshirvan ${ }^{1}$, Parvin Rafieinia ${ }^{2}$, Seyed Mosa Tabatabaee $^{3}$

1. Student of cognitive psychology (M.A), Semnan University, Semnan, Iran

2. Assistant professor of clinical psychology, Semnan University, Semnan, Iran

3. Assistant professor of cognitive science, Semnan University, Semnan, Iran

\begin{abstract}
Aims: Adolescence is a critical period because the brain is involved in the process of maturation that entails cognitive functions. On the way of maturation, an individual's inhibitory control undergoes many changes and becomes vulnerable to different thrill-seeking like smoking, drinking, and so on. Smoking is highly prevalent among teenagers that are trying to take control of their behaviors in order to join society. They experience antisocial behavior too which is a trait that can lead adolescents to addiction. This trait is an inevitable part of psychopathy. Inhibitory deficits and psychopathy have been widely reported in addiction studies. The current study tried to investigate the relationship between psychopathic traits and behavioral inhibition between male smokers and non-smoker teenage students.
\end{abstract}

Materials \& Methods: Statistical sample of this research is 62 teenage students aged 17 years that are divided into smoker and non-smoker groups. The participants have been chosen through random sampling from the population of 10 high schools. The data have been gathered in Kordkoy and Gorgan in Golestan province. Behavioral bias has been measured by Go/NoGo task and psychopathic traits through youth psychopathic traits inventory. Also, the short form of Wechsler Adult Intelligence Scale test has been executed and used as a control variable. 
Findings: A meaningful difference has been found between the performance of smoker and non-smoker groups in Go/No Go task and psychopathic traits that are smokers performed weaker in comparison with non-smokers and psychopathic traits of smokers were meaningfully higher than non-smokers. On the other hand, there was no significant difference between these two groups in their Wechsler Adult Intelligence Scale scores.

Conclusion: The results have shown that smokers have higher psychopathic traits and lower behavioral inhibition when compared with their non-smoker peers. According to the results of current research, smoking can decline the cognitive functions.

Keywords: response inhibition, behavioral inhibition, psychopathy traits, Go/NoGo task, smokers

Post address: Semnan University, opposite of Sookan Park, Pardis No 1, Central building

Postal code: $35131-19111$

Tel: $023-31530000$

Mail: navazeshmarandi78@gmail.com, navazeshms@semnan.ac.ir 


\section{Introduction}

Tobacco is a ruthless and vicious murderer that takes more than 8 million people's lives each year. More than 80 percent of the tobacco users live in low- and middleincome countries (Health Organization, 2018). Addictive drugs are taken as a mood booster or intensifier by individuals like staying energetic at parties or heighten the level of happiness or relieve distress (Hyman \& Malenka, 2001). When these drugs are being used or abused recurrently and after a period of time the users experience and state of tendency and dependency to use the specific drug or a combination of drugs (Cami \& Farré, 2003). This state comes with a consequence which is called addiction and symptom, or in other words, withdrawal symptoms when the drug is not available or using becomes impossible. Many studies have been shown that addiction has some partners in crime such as impaired executive (inhibitory) control over behavior, aberrant learning, and incentive-sensitization to drug use and drug cues (e.g. Robinson \& Berridge 2008; Everitt \&Robbins 2016; Badiani, Berridge, Heilig, Nutt, \& Robinson, 2018; Volkow \& Li, 2004; Vandaele \& Janak, 2018).

The onset of psychoactive drug use starts during late childhood or early adolescence and occurs in a relatively predictable sequence (Kandel and Kandel, 2015). Adolescent start their drug experiment with those drugs that are available and easily accessible for adults legally like alcohol and tobacco. And the other side of the experiment goes to the path of the illegal part of drugs like marijuana and so on (Keyes, Rutherford, \& Miech, 2019). According to the literature, some people test marijuana or alcohol before smoking, which states the fact that the onset and sequence of drug use happens after smoking. This hypothesis is known as the "gateway hypothesis" (Kandel, 1975), and ccording to this hypothesis, there are two opening gates for addiction, cigarettes and alcohol. There is a consensus 
among some researchers that tobacco use disorder (TUD) causes some damages to the modulation of cognitive processes, emotions, and reward circuit in the brain, which indicates the fact that TUD can impose long-lasting and wide changes in the brain and its circuits (Sutherland \& Stein, 2018; Koob \& Volkow, 2010; Kalivas, 2002; Fedota, Sutherland, Salmeron, Ross, Hong, \& Stein, 2015).

Behavioral inhibition is a very well-known cognitive factor that plays a significant role in TUD (Potter, Newhouse, 2004). According to Barkley (1997), behavioral inhibition owns three components: the capacity to inhibit pre-potent (learned) responses, creating a delay in responding to an event; the capacity to interrupt ongoing responses due to performance feedback, and the protection of this delay in responding (the ability to maintain the delay in responding that was created by inhibiting the responses.

To sum up, cognitive/behavioral inhibition indicates a sort of delaying impulse or urge to take action, and/or capability to abstain from responding because of surroundings cues (Potter \& Newhouse, 2004). It has been shown that deficits in behavioral inhibition and its neural correlates can cause compulsive and harmful behaviors that are associated with addiction and impediment of free will (Goldstein \&Volkow, 2011; Linhartová, Kuhn, Damborská, Lamoš, Mikl, Barteček, \& Bareš, 2017). During adolescence, the capacity of behavioral inhibition undergoes many changes due to brain evolution and growth which means there is a constant unbalanced state of controlling or inhibiting the behavior. Another reason for this unsteady state is the expansion of prefrontal regions that are vital for behavioral inhibition (Anokhin \& Golosheykin, 2016). Hence, the ability to control or inhibit the behaviors improves from late childhood to adolescence (Schachar \& Logan, 1990). Mashhoon, Betts, Farmer \& Lukas (2018) state that the capacity of inhibition differs between late-onset smokers, non-smokers, and early-onset 
smokers. The result showed that early-onset smokers made more mistakes in the inhibition part (No Go) of the Go/No Go task compared to the other two groups. On the other hand, Riccio, Waldrop, Reynolds, Lowe (2001) observed that nicotine in non-smokers can decrease the errors in inhibition tasks. Bekker, Böcker, Van Hunsel, Van Den Berg, Kenemans (2005) reported their result contradicted the common hypothesis of declining behavioral inhibition in smokers. Therefore, they observed that nicotine actually decreases the inhibition error in the stop-signal test in the smokers' group, which means improvement of controlled performance in smokers (Bekker et al., 2005).

The tendency to smoke cigarettes and take drugs includes different reasons, and psychopathy is one of these reasons. Cleckley (1976) in his book "The Mask of Sanity" defines Psychopathy as a pervasive personality disorder. Heritage (2017) describes some fundamental features for psychopathy such as low fear, interpersonal dominance, diminished empathy, manipulation/deception, and superficial charm mixed with impulsivity, aggression, sensation/reward seeking, and increased negative emotionality. Individuals with psychopathy disorder show behavioral deviations and poor control that increases the chance of drug addiction (Heritage, 2017). Melanko, Leraas, Collins, Fields, Reynolds (2009) compared smoker and non-smoker teenagers in terms of psychopathic traits, antisocial behavior, and impulsivity. They concluded that the smoker group showed more psychopathic traits, antisocial behavior, and impulsivity than the non-smoker group. Hoffman, Jacobs, Dennis, McCready, Hickok, Smith, Kohno (2020) studied the relationship between addiction and psychopathy from the neurological and anatomical perspective. He found there are similar abnormalities in ventral striatal function and cortico-striatal resting-state functional connectivity (RSFC) both in psychopathy and addiction. And these abnormalities are responsible for criminal 
behavior, decision making, and impulse control. The current study aims to investigate whether behavioral inhibition and psychopathic traits differ between smoker and non-smoker groups.

\section{Methodology}

All participants were recruited from the local high schools in Gorgan City and Kordkoy City, Golestan province, Iran. 62 male teenage students were selected through a random selection from an accessible population. 32 smokers were assessed according to the DSM-5 criteria for STUD. According to these criteria, someone is considered a smoker or experiencing STUD that at least has experienced two of the mentioned criteria in the past 12 months.

Inclusion criteria for this study were male students who are 17 years old (for both groups) and having at least two criteria from DSM-5 criteria for tobacco use disorder in 12 months' time range (for the smokers' group). The exclusion criteria were severe mental disorders and cognitive deficits, subjects use cigarettes with other drugs like alcohol or marijuana, Taking Psychiatric medication, and being in medical or psychiatric interventions.

\section{Procedure}

All participants read and filled in a Consent Form. First, Go/NoGo was introduced to them, and then a trial round was performed; the main experiment performed afterward. After that, the four-subtest short version of WASI-R was explained by the researcher and performed one by one (Vocabulary, Block Design, Arithmetic, and Picture Arrangement). In the end, participants filled in the YPI questionnaire. The whole process took 50 minutes for each participant.

\section{Tasks}


Go/No-Go task: This task is a reliable paradigm to measures response inhibition, and in many nicotine addiction studies has been used (Roberts, Rau, Lutzenberger, \& Birbaumer, 1994; Kozink, Kollins \& McClernon, 2010; Gießing, Thiel, Alexander-Bloch, Patel, \& Bullmore, 2013; Lesage, Sutherland, Ross, Salmeron, Stein, 2020). The subject must respond to one type of these stimuli (Go), and avoid responding to another one (No-Go). Since the number and frequency of Go stimuli are more than No-Go; the subject is more probable and ready to respond than avoiding. There are two sorts of errors that are measured: first, commission errors occur when the subject is not supposed to press any keys because the No-Go stimulus is being presented (or creating false alarms). Second, omission errors occur when the subject is supposed to press a key because the Go stimulus is being presented (also known as misses). And reaction time is also measured and shows how fast or late the subject performs in a Go or No-Go situation. In the current study, a computerized version of Go/NoGo used. In the computerized version of Go/NoGo, the trial stage comes first and clarifies the instructions. According to these instructions, two rectangles appear on the screen in "one in white and the other in blue" or "white and yellow" randomly, and for a short period $(0.2 \mathrm{sec})$, and you must pay attention carefully to these pair of rectangles.

If one of the rectangles is in yellow, do not press any key, but if one rectangle is in blue and appears on the right side of the screen, press "?", Come and press "z" when you see the rectangle appear on the left side of the screen. To start the process, the subject must press the "Enter" key. After the trial stage, the main stage begins that presents 40 trials for the subject.

Youth psychopathic traits inventory (YPI): YPI is a self-report questionnaire that includes 50 items; responses are given on a 4-point Likert scale ranging from "Does not apply at all" to"Applies very well" (Andershed, Kerr, Stattin, \& 
Evander, 2002) and measures psychopathic traits among 12-18-year-olds. YPI is constructed based upon 3 factors and 3 domains; Grandiose/Manipulative (Interpersonal domain), Callous /Unemotional (Affective), and Impulsive/Irresponsible (Behavioral). It measures each psychopathic trait with five self-report items making up 10 internally consistent subscales (Andershed, Hodgins, \& Tengström, 2007).

Andershed, Kerr et al. (2002) found that the YPI's 10 scales were internally consistent ( $1 / 40.66-0.93$, average $1 / 40.74)$ and conformed very well with their hypothesized three-factor structure (see Cook \& Michie, 2001) of Interpersonal, Affective, and Lifestyle dimensions (CFI 1/40.98 for both boys and girls) (Skeem \& Cauffman, 2003).

Wechsler Adult Intelligence Scale-Revised: The Wechsler Adult Intelligence Scale is the most popular tool for estimating IQ. The Wechsler Adult Intelligence Scale-Revised (WAIS-R; Wechsler, 1981) is a revised version of the Wechsler Adult Intelligence Scale first published in 1955. Wechsler (1981) found that the highest split-half reliability was for Vocabulary (.96), and the lowest split-half reliability was for Picture Arrangement (.52). Silverstein (1982) introduced two (Vocabulary and Block Design) and four subtests (Vocabulary, Block Design, Arithmetic, and Picture Arrangement) short forms of the WASI-R that is widely used in studies considering mental problems (Franzen, 2000). In a study, the correlation between four subtests short form and WAIS-R Full-Scale IQ reported highly significant $(\mathrm{r}(53)=.95)$. According to this result, the four subtests short form appear to have clinical utility as a screening device to identify patients with atypical cognitive functioning (Ryan, Georgemiller, \& McKinney, 1984). Four subtests of WASI-R were employed to control the effect of intelligence on two groups' performances. 


\section{Results}

Parametric statistics, including analysis of covariance, multivariate analysis of variance, and independent t-test, were utilized for data analysis. Therefore, the normality assumption was tested using Shapiro-wilk test, and the result showed that all the variables in the study had a normal distribution $(\alpha=0.01)$. The homogeneity of variances was also examined using Levene's test, and as table 1 shows, in all variables of the study (except the behavioral inhibition), the variance of the two groups is equal. However, as the number of subjects in the two groups is equal, the heterogeneity of the two groups' variances in the behavioral inhibition variable does not pose a problem for the use of parametric tests.

Table1. Leven test's for homogeneity of variances in groups

\begin{tabular}{|c|c|c|c|c|}
\hline variables & $F$ & df1 & df2 & Sig. \\
\hline inhibition & 36.30 & 1 & 60 & 0.001 \\
\hline psychopathy & 0.07 & 1 & 60 & 0.78 \\
\hline Dishonest charm & 0.07 & 1 & 60 & 0.79 \\
\hline Grandiosity & 1.08 & 1 & 60 & 0.30 \\
\hline lying & 6.61 & 1 & 60 & 0.01 \\
\hline manipulation & 0.00 & 1 & 60 & 0.96 \\
\hline remorselessness & 0.03 & 1 & 60 & 0.85 \\
\hline unemotionality & 0.15 & 1 & 60 & 0.69 \\
\hline callousness & 0.71 & 1 & 60 & 0.40 \\
\hline Thrill seeking & 0.51 & 1 & 60 & 0.47 \\
\hline impulsiveness & 0.31 & 1 & 60 & 0.58 \\
\hline
\end{tabular}




\begin{tabular}{|c|l|l|l|l|}
\hline irresponsibility & 0.00 & 1 & 60 & 0.96 \\
\hline
\end{tabular}

Table 2.Descriptive statistics

\begin{tabular}{|c|c|c|c|c|}
\hline \multirow{2}{*}{ Variables } & \multicolumn{4}{|c|}{ Group } \\
\cline { 2 - 5 } & \multicolumn{2}{|c|}{ smoker } & mean & SD \\
\cline { 2 - 5 } & mean & SD & 29.03 & 12.16 \\
\hline inhibition & 15.00 & 5.24 & 98.48 & 16.64 \\
\hline psychopathy & 114.48 & 17.01 & 9.35 & 2.88 \\
\hline Dishonest & 10.77 & 3.26 & 13.16 & 2.69 \\
\hline charm & & & 7.45 & 2.07 \\
\hline Grandiosity & 11.87 & 3.12 & 8.93 & 3.06 \\
\hline lying & 10.41 & 3.52 & 10.16 & 2.77 \\
\hline manipulation & 10.67 & 3.10 & 11.00 & 2.95 \\
\hline remorselessness & 11.83 & 2.59 & 8.51 & 2.77 \\
\hline unemotionality & 11.96 & 3.016 & & 3.16 \\
\hline
\end{tabular}




\begin{tabular}{|c|c|c|c|c|}
\hline impulsiveness & 12.25 & 3.06 & 9.22 & 2.76 \\
\hline irresponsibility & 10.90 & 2.73 & 7.51 & 2.65 \\
\hline
\end{tabular}

According to the table above, the mean of the two groups is not equal in all variables, but in order to determine whether these differences are significant or not, appropriate statistical methods must be used.

The univariate analysis of covariance was employed to compare the smoker and non-smoker groups in the inhibition score and equate the two groups in terms of intelligence quotient (IQ).

IQ scores were entered into the analysis as an auxiliary variable. The results of the covariance analysis to compare the smoker and non-smoker groups in the inhibition score are as follows.

Table 3.ANCOVA for comparison of behavioral inhibition among smoker and non-smoker teenage students

\begin{tabular}{|c|c|c|c|c|c|c|}
\hline source & SS & DF & MS & F & Sig. & eta \\
\hline $\begin{array}{c}\text { Covariate } \\
\text { variable: IQ }\end{array}$ & 31.05 & 1 & 31.05 & 0.35 & 0.55 & 0.001 \\
\hline group & 2914.88 & 1 & 2914.88 & 32.87 & 0.00 & 0.35 \\
\hline
\end{tabular}

Based on table 3, there is a significant difference between the two groups in terms of inhibition score as the average score of inhibition for the smoker group (15.00) is significantly lower than the average score of inhibition for the non-smoker group (29.03). 
The Multivariate analysis of variance (MANOVA) test was applied to compare smoking and non-smoking students in terms of psychopathic traits. The value of Box's $M$ statistics was not significant (Box's $\mathrm{M}=70.54 ; \mathrm{F}=1.054 ;$ df: 55 \& 11625.51; Sig: 0.36); hence the assumption of homogeneity of the error covariance matrix has been met. Moreover, considering the multiple statistics for comparing the smoking and non-smoking groups in the psychopathic traits, as well as the amount of Wilkes' lambda $(F=3.80 ; p<0.001)$, seemingly there is a significant difference between the two groups in terms of the linear composition of the traits of psychopathy; meaning that there is no prohibition on using multivariate analysis of variance.

Table 4. MANOVA for comparison of two groups in psychopathy sub-scales

\begin{tabular}{|c|c|c|c|c|c|c|c|}
\hline source & Sub-scales & SS & DF & MS & F & Sig. & eta \\
\hline group & $\begin{array}{c}\text { Dishonest } \\
\text { charm }\end{array}$ & 31.22 & 1 & 31.22 & 3.29 & 0.07 & 0.05 \\
\cline { 2 - 8 } & Grandiosity & 25.80 & 1 & 25.80 & 3.026 & 0.08 & 0.04 \\
\cline { 2 - 8 } & lying & 136.51 & 1 & 136.51 & 16.27 & 0.001 & 0.21 \\
\cline { 2 - 8 } & manipulation & 47.032 & 1 & 47.032 & 4.94 & 0.03 & 0.07 \\
\cline { 2 - 8 } & remorselessness & 43.613 & 1 & 43.613 & 6.05 & 0.01 & 0.09 \\
\cline { 2 - 8 } & unemotionality & 14.516 & 1 & 14.516 & 1.62 & 0.20 & 0.02 \\
\cline { 2 - 8 } & callousness & 10.081 & 1 & 10.08 & 1.56 & 0.21 & 0.025 \\
\cline { 2 - 8 } & Thrill seeking & 34.12 & 1 & 34.12 & 3.58 & 0.06 & 0.05 \\
\cline { 2 - 8 } & impulsiveness & 142.51 & 1 & 142.51 & 16.72 & 0.001 & 0.21 \\
\hline
\end{tabular}




\begin{tabular}{|l|l|l|l|l|l|l|l|}
\hline & irresponsibility & 177.82 & 1 & 177.82 & 24.44 & 0.001 & 0.28 \\
\hline
\end{tabular}

According to Table 4, there is a significant difference between the two groups in the components of lying, manipulation, remorselessness, impulsivity, and irresponsibility. The average of the smoker group in these subscales is significantly higher than that of the non-smoker. There is no significant difference between the smokers and non-smokers groups in the other subscales (Dishonest charm, Grandiosity, unemotionality, callousness, thrill-seeking).

An independent t-test was employed to compare the two groups in the total psychopathy score, as follows:

Table 5- independent T-test to compare two groups in total score of psychopathy

\begin{tabular}{|c|c|c|c|c|c|c|c|}
\hline variable & group & $\mathrm{N}$ & mean & SD & df & t & Sig. \\
\hline psychopathy & smoker & 31 & 114.48 & 17.01 & 30 & 3.74 & 0.001 \\
\cline { 2 - 8 } & $\begin{array}{c}\text { Non- } \\
\text { smoker }\end{array}$ & 31 & 98.48 & 16.64 & & & \\
\hline
\end{tabular}

Based on table 5, there is a significant difference between smokers and nonsmokers groups in terms of the mean score of total psychopathy, and the mean of the smoking group is significantly higher than that of the non-smoking group.

\section{Discussion}

This study aimed to compare behavioral inhibition and psychopathic traits of smokers and non-smokers. By analyzing the components of Go/No-Go software 
that was used to measure behavioral inhibition, it was found that there is a significant difference between the two groups in terms of inhibition score, and the average inhibition score of the smoking group is significantly lower than the average inhibition score of the non-smoking group. Overall, the smoking group had a lower response inhibition than the non-smoking group.

In many studies, behavioral inhibition scores of smokers reported to be lower than non-smokers (Heritage\& Benning, 2013; Iacono, 2002; Munro, Dywan, Harris, McKee, Unsal, Segalowitz, 2007; Vitale, Newman, Bates, Goodnight, Dodge, \& Pettit, 2005). However, in several studies, no significant difference was observed between the inhibition scores of smokers and non-smokers (Bekker et al., 2005; Kleykamp, Jennings, Blank, \& Eissenberg 2005; Mogg and Bradley, 2002; Munafò, Mogg, Roberts, Bradley, \& Murphy, 2003; Ettinger, \& Kumari, 2019; Hatchard, Fried, Hogan, Cameron, \& Smith, 2014; Dinn, Aycicegi, \& Harris, 2004; Galván, Poldrack, Baker, McGlennen, \& London, 2011). For example, Ettinger \& Kumari (2019) observed that nicotine improves essential functions of attention such as orientation and alertness; thus, no significant difference was observed between smokers and non-smokers in that regard.

The results of this study support the mentioned researches in the field of response inhibition. The lower level of inhibition prompts a higher rate of addiction or substance use disorder (Lilienfeld, Latzman, Watts, Smith, \& Dutton, 2014). Various studies have reported poor performance of psychopathic individuals in inhibition tests. They have shown that impaired behavioral inhibition is a hallmark of psychopathic individuals and that lack of inhibition can be one of several factors influencing the unsuccessful treatment of these individuals in the field of abstinence from addiction and criminal habits (Holland, Cousson, Patterson, Newman, 1993; Kyle, Smith, Hare, Liddell, 2000). 
It was observed that there was a significant difference between the two groups in the components of lying, manipulation, remorselessness, impulsivity, irresponsibility. So the average of the smoking group in these subscales was significantly higher than the non-smoking group. Heritage (2017) states that Psychopathy disorder increases the rate of drug addiction.

Behaviors such as interpersonal violence and propensity to commit crimes are also integral to this disorder. One of the structural factors of anti-socialism is the sociopath-impulsive factor, and this factor has the highest correlation and connection with criminal behaviors, whether violently or non-violently. It is also associated with a decrease in individuals' stability of educational and professional life. It has also been shown to correlate positively with other externalizing behaviors, such as substance abuse (Anestis, Anestis, \& Joiner, 2009; Verona, Sprague, \& Sadeh, 2012; Walters, 2012). Individuals with high levels of sociopathimpulsive factor showed reduced neural processing in the face of non-oriented stimuli, and their dopamine levels increase when predicting a reward, and in general, their skin's electrical activity decreases in response to emotional stimuli (Benning, Patrick, \& Yakonu, 2005; Buckholtz, Treadway, Cowan, Woodward, Ansari, \& Zald, (2010); Carlson, \& Thái, (2010); Patrick, Bradley, \& Lang, 1993). Behaviorally, Fearless Dominance is associated with increased thrill and sensationseeking behavior (Ross, Benning, Patrick, Thompson, and Tarston, 2009).

Conduct disorder and antisocial personality disorder are behavioral features of psychopathy disorder, and the disorder itself is a factor that plays a crucial role in adolescents and adults' tendency towards drugs (Melanko et al., 2009; Burke, Loeber, \& Lahey, 2007; Gacono, Nieberding, Owen, Rubel, \& Bodholdt, 2001; Frick, \& Dickens, 2006; Sanchez de Ribera, Kavish, Katz, \& Boutwell, 2019; Goulter, McMahon, Pasalich, \& Dodge, 2019). Therefore, it can be concluded that 
high levels of psychopathic traits in adolescents can be considered as one of the critical factors that participate in the desire to smoke and nicotine addiction. The results of the present study are in line with and support previous researches. Higher levels of psychopathic traits have reported among smoker individuals than nonsmokers (Sadeh, Vderona, 2008; Blair\& Mitchel, 2009; Lorenz and Newman, 2002; Heritage, 2017; Hamghala, Kosson, Westerman \& Hodgins, 2015; Drobes, Oliver, Correa, \& Evans, 2019).

Given the limitations of sampling and the lack of an extensive age and gender distribution, it is recommended that in future research in the scope of psychopathy and addiction, age and gender diversity should be considered. On the one hand, by using software designed exclusively for investigating addiction, the results will be obtained in a more specialized way, and it is suggested using software made for specific purposes. On the other hand, by using different techniques, such as biomarkers and Eye tracker, accompanied by cognitive tests, the results can be delivered to other researchers with higher quality. Furthermore, the use of state-ofthe-art technologies such as fMRI can help to provide a deeper understanding of the brain and behavioral structures while performing cognitive tests.

\section{References}

Andershed, H. A., Kerr, M., Stattin, H., \& Levander, S. (2002). Psychopathic traits in non-referred youths: A new assessment tool.

Andershed, H., Hodgins, S., \& Tengström, A. (2007). Convergent validity of the youth psychopathic traits inventory (YPI) association with the psychopathy 
checklist: youth version (PCL: YV). Assessment, 14(2), 144-154.

Anestis, M. D., Anestis, J. C., \& Joiner, T. E. (2009). Affective considerations in antisocial behavior: An examination of negative urgency in primary and secondary psychopathy. Personality and Individual Differences, 47(6), 668670.

Anokhin, A. P., \& Golosheykin, S. (2016). Neural correlates of response inhibition in adolescents prospectively predict regular tobacco smoking. Developmental Neuropsychology, 41(1-2), 22-37.

Badiani, A., Berridge, K. C., Heilig, M., Nutt, D. J., \& Robinson, T. E. (2018). Addiction research and theory: a commentary on the Surgeon General's Report on alcohol, drugs, and health. Addiction Biology, 23(1), 3-5.

Barkley, R. A. (1997). Behavioral inhibition, sustained attention, and executive functions: constructing a unifying theory of ADHD. Psychological Bulletin, 121(1), 65 .

Bekker, E. M., Böcker, K. B. E., Van Hunsel, F., Van Den Berg, M. C., \& Kenemans, J. L. (2005). Acute effects of nicotine on attention and response inhibition. Pharmacology Biochemistry and Behavior, 82(3), 539-548.

Benning, S. D., Patrick, C. J., \& Iacono, W. G. (2005). Psychopathy, startle blink modulation, and electrodermal reactivity in twin men. Psychophysiology, 42(6), 753-762. 
Blair, R. J. R., \& Mitchell, D. G. V. (2009). Psychopathy, attention and emotion. Psychological Medicine, 39(4), 543.

Buckholtz, J. W., Treadway, M. T., Cowan, R. L., Woodward, N. D., Li, R., Ansari, M. S., ... \& Zald, D. H. (2010). Dopaminergic network differences in human impulsivity. Science, 329(5991), 532-532.

Burke, J. D., Loeber, R., \& Lahey, B. B. (2007). Adolescent conduct disorder and interpersonal callousness as predictors of psychopathy in young adults. Journal of Clinical Child and Adolescent Psychology, 36(3), 334-346.

Cami, J., \& Farré, M. (2003). Drug addiction. New England Journal of Medicine, 349(10), 975-986.

Carlson, S. R., \& Thái, S. (2010). ERPs on a continuous performance task and selfreported psychopathic traits: P3 and CNV augmentation are associated with Fearless Dominance. Biological Psychology, 85(2), 318-330.

Caswell, A. J., Bond, R., Duka, T., \& Morgan, M. J. (2015). Further evidence of the heterogeneous nature of impulsivity. Personality and Individual Differences, 76, 68-74.

Cleckley, H. E. R. V. E. Y. (1976). The Mask of Sanity. 1941. St Louis, Mosby. Cooke, D. J., \& Michie, C. (2001). Refining the construct of psychopathy: towards a hierarchical model. Psychological Assessment, 13(2), 171.

Dinn, W. M., Aycicegi, A., \& Harris, C. L. (2004). Cigarette smoking in a student 
sample: neurocognitive and clinical correlates. Addictive Behaviors, 29(1), 107-126.

Dolan, M. C., \& Rennie, C. E. (2006). Reliability and validity of the psychopathy checklist: Youth version in a UK sample of conduct disordered boys. Personality and Individual Differences, 40(1), 65-75.

Drobes, D. J., Oliver, J. A., Correa, J. B., \& Evans, D. E. (2019). Attentional Bias and Smoking. In Neuroscience of Nicotine (pp. 145-150). Academic Press.

Ewing, S. W. F., Sakhardande, A., \& Blakemore, S. J. (2014). The effect of alcohol consumption on the adolescent brain: A systematic review of MRI and fMRI studies of alcohol-using youth. NeuroImage: Clinical, 5, 420-437.

Everitt, B. J., \& Robbins, T. W. (2016). Drug addiction: updating actions to habits to compulsions ten years on. Annual Review of Psychology, 67, 23-50.

Fedota, J. R., Sutherland, M. T., Salmeron, B. J., Ross, T. J., Hong, L. E., \& Stein, E. A. (2015). Reward anticipation is differentially modulated by varenicline and nicotine in smokers. Neuropsychopharmacology, 40(8), 2038-2046.

Franzen, M. D. (2000). The Wechsler Adult Intelligence Scale-Revised and Wechsler Adult Intelligence Scale-III. In Reliability and Validity in Neuropsychological Assessment (pp. 55-70). Springer, Boston, MA.

Frick, P. J., \& Dickens, C. (2006). Current perspectives on conduct disorder. Current psychiatry reports, 8(1), 59-72. 
Gall, M. D., Borg, W. R., \& Gall, J. P. (1996). Educational research: An introduction. Longman Publishing.

Galván, A., Poldrack, R. A., Baker, C. M., McGlennen, K. M., \& London, E. D. (2011). Neural correlates of response inhibition and cigarette smoking in late adolescence. Neuropsychopharmacology, 36(5), 970-978.

Gacono, C. B., Nieberding, R. J., Owen, A., Rubel, J., \& Bodholdt, R. (2001). Treating conduct disorder, antisocial, and psychopathic personalities.

Gao, Y., \& Raine, A. (2009). P3 event-related potential impairments in antisocial and psychopathic individuals: A meta-analysis. Biological Psychology, 82(3), 199-210.

Gießing, C., Thiel, C. M., Alexander-Bloch, A. F., Patel, A. X., \& Bullmore, E. T. (2013). Human brain functional network changes associated with enhanced and impaired attentional task performance. Journal of Neuroscience, 33(14), 59035914.

Goldstein, R. Z., \& Volkow, N. D. (2011). Dysfunction of the prefrontal cortex in addiction: neuroimaging findings and clinical implications. Nature Reviews Neuroscience, 12(11), 652-669.

Goulter, N., McMahon, R. J., Pasalich, D. S., \& Dodge, K. A. (2019). Indirect effects of early parenting on adult antisocial outcomes via adolescent conduct disorder symptoms and callous-unemotional traits. Journal of Clinical Child \& 
Adolescent Psychology, 1-13.

Ettinger, U., \& Kumari, V. (2019). Effects of nicotine on inhibitory control in humans. In Neuroscience of Nicotine (pp. 151-158). Academic Press.

Hatchard, T., Fried, P. A., Hogan, M. J., Cameron, I., \& Smith, A. M. (2014). Marijuana use impacts cognitive interference: an fMRI investigation in young adults performing the counting Stroop task. Journal of Addiction Research \& Therapy, 5(4), 197-203.

Hemphälä, M., Kosson, D., Westerman, J., \& Hodgins, S. (2015). Stability and predictors of psychopathic traits from mid-adolescence through early adulthood. Scandinavian Journal of Psychology, 56(6), 649-658.

Heritage, A. J., \& Benning, S. D. (2013). Impulsivity and response modulation deficits in psychopathy: Evidence from the ERN and N1. Journal of Abnormal Psychology, 122(1), 215.

Heritage, A. J. (2017). Interactive Cognitive-Affective Deficits: A Theory of the Psychopathic Personality. Vanderbilt University.

Hoffman, W. F., Jacobs, M. B., Dennis, L. E., McCready, H. D., Hickok, A. W., Smith, S. B., \& Kohno, M. (2020). Psychopathy and corticostriatal connectivity: the link to criminal behavior in methamphetamine dependence. Frontiers in Psychiatry, 11, 90.

Howland, E. W., Kosson, D. S., Patterson, C. M., \& Newman, J. P. (1993). 
Altering a dominant response: Performance of psychopaths and lowsocialization college students on a cued reaction time task. Journal of Abnormal Psychology, 102(3), 379.

Hyman, S. E., \& Malenka, R. C. (2001). Addiction and the brain: the neurobiology of compulsion and its persistence. Nature Reviews Neuroscience, 2(10), 695703.

Iacono, W. G., Carlson, S. R., Malone, S. M., \& McGue, M. (2002). P3 eventrelated potential amplitude and the risk for disinhibitory disorders in adolescent boys. Archives of General Psychiatry, 59(8), 750-757.

Kalivas, P. W. (2002). Neurocircuitry of addiction. Neuropsychopharmacology: The fifth generation of progress, 95, 1357-1366.

Kandel, D. (1975). Stages in adolescent involvement in drug use. Science, 190(4217), 912-914.

Kandel, D., \& Kandel, E. (2015). The Gateway Hypothesis of substance abuse: developmental, biological and societal perspectives. Acta Paediatrica, 104(2), 130-137.

Keyes, K. M., Rutherford, C., \& Miech, R. (2019). Historical trends in the grade of onset and sequence of cigarette, alcohol, and marijuana use among adolescents from 1976-2016: Implications for "Gateway" patterns in adolescence. Drug and Alcohol Dependence, 194, 51-58. 
Kiehl, K. A., Smith, A. M., Hare, R. D., \& Liddle, P. F. (2000). An event-related potential investigation of response inhibition in schizophrenia and psychopathy. Biological Psychiatry, 48(3), 210-221.

Kleykamp, B. A., Jennings, J. M., Blank, M. D., \& Eissenberg, T. (2005). The effects of nicotine on attention and working memory in never-smokers. Psychology of Addictive Behaviors, 19(4), 433.

Koob, George F., and Nora D. Volkow. "Neurocircuitry of addiction." Neuropsychopharmacology 35, no. 1 (2010): 217-238.

Kozink, R. V., Kollins, S. H., \& McClernon, F. J. (2010). Smoking withdrawal modulates right inferior frontal cortex but not presupplementary motor area activation during inhibitory control. Neuropsychopharmacology, 35(13), 26002606.

Lawing, K., Frick, P. J., \& Cruise, K. R. (2010). Differences in offending patterns between adolescent sex offenders high or low in callous - unemotional traits. Psychological Assessment, 22(2), 298.

Lesage, E., Sutherland, M. T., Ross, T. J., Salmeron, B. J., \& Stein, E. A. (2020). Nicotine dependence (trait) and acute nicotinic stimulation (state) modulate attention but not inhibitory control: converging fMRI evidence from Go-Nogo and Flanker tasks. Neuropsychopharmacology, 45(5), 857-865.

Lilienfeld, S. O., Smith, S. F., \& Watts, A. L. (2016). The perils of unitary models of the etiology of mental disorders-The response modulation hypothesis of psychopathy as a case example: Rejoinder to Newman and Baskin-Sommers 
(2016).

Linhartová, P., Kuhn, M., Damborská, A., Lamoš, M., Mikl, M., Barteček, R., ... \& Bareš, M. (2017). Neural correlates of behavioral inhibition in healthy people and in patients with borderline personality disorder and ADHD. European Psychiatry, 41(S1), S346-S347.

Lorenz, A. R., \& Newman, J. P. (2002). Deficient response modulation and emotion processing in low-anxious Caucasian psychopathic offenders: results from a lexical decision task. Emotion, 2(2), 91.

Mashhoon, Y., Betts, J., Farmer, S. L., \& Lukas, S. E. (2018). Early onset tobacco cigarette smokers exhibit deficits in response inhibition and sustained attention. Drug and Alcohol Dependence, 184, 48-56.

Melanko, S., Leraas, K., Collins, C., Fields, S., \& Reynolds, B. (2009). Characteristics of psychopathy in adolescent nonsmokers and smokers: Relations to delay discounting and self reported impulsivity. Experimental and Clinical Psychopharmacology, 17(4), 258.

Mogg, K., \& Bradley, B. P. (2002). Selective processing of smoking-related cues in smokers: manipulation of deprivation level and comparison of three measures of processing bias. Journal of Psychopharmacology, 16(4), 385392.

Munafò, M., Mogg, K., Roberts, S., Bradley, B. P., \& Murphy, M. (2003). Selective processing of smoking-related cues in current smokers, ex-smokers and never-smokers on the modified Stroop task. Journal of 
Psychopharmacology, 17(3), 310-316.

Munro, G. E., Dywan, J., Harris, G. T., McKee, S., Unsal, A., \& Segalowitz, S. J. (2007). Response inhibition in psychopathy: the frontal N2 and P3.

Neuroscience Letters, 418(2), 149-153.

Patrick, C. J., Bradley, M. M., \& Lang, P. J. (1993). Emotion in the criminal psychopath: startle reflex modulation. Journal of Abnormal Psychology, 102(1), 82.

Potter, A. S., \& Newhouse, P. A. (2004). Effects of acute nicotine administration on behavioral inhibition in adolescents with attention-deficit/hyperactivity disorder. Psychopharmacology, 176(2), 183-194.

Riccio, C. A., Waldrop, J. J., Reynolds, C. R., \& Lowe, P. (2001). Effects of stimulants on the continuous performance test (CPT) implications for CPT use and interpretation. The Journal of Neuropsychiatry and Clinical Neurosciences, 13(3), 326-335.

Roberts, L. E., Rau, H., Lutzenberger, W., \& Birbaumer, N. (1994). Mapping P300 waves onto inhibition: Go/No $\square$ Go discrimination. Electroencephalography and Clinical Neurophysiology/Evoked Potentials Section, 92(1), 44-55.

Robinson, T. E., \& Berridge, K. C. (2008). The incentive sensitization theory of addiction: some current issues. Philosophical Transactions of the Royal Society B: Biological Sciences, 363(1507), 3137-3146. 
Ross, S. R., Benning, S. D., Patrick, C. J., Thompson, A., \& Thurston, A. (2009). Factors of the Psychopathic Personality Inventory: Criterion-related validity and relationship to the BIS/BAS and Five-Factor Models of Personality. Assessment, 16(1), 71-87.

Ryan, J. J., Georgemiller, R. J., \& McKinney, B. E. (1984). Application of the four-subtest WAIS-R short form with an older clinical sample. Journal of Clinical Psychology, 40(4), 1033-1036.

Sadeh, N., \& Verona, E. (2008). Psychopathic personality traits associated with abnormal selective attention and impaired cognitive control. Neuropsychology, 22(5), 669.

Sanchez de Ribera, O., Kavish, N., Katz, I. M., \& Boutwell, B. B. (2019). Untangling intelligence, psychopathy, antisocial personality disorder, and conduct problems: A meta-analytic review. European Journal of Personality, 33(5), 529-564.

Schachar, R., \& Logan, G. D. (1990). Impulsivity and inhibitory control in normal development and childhood psychopathology. Developmental Psychology, 26(5), 710.

Silverstein, A. B. (1982). Two-and four-subtest short forms of the Wechsler Adult Intelligence Scale-Revised. Journal of Consulting and Clinical Psychology, $50(3), 415$.

Skeem, J. L., \& Cauffman, E. (2003). Views of the downward extension: 
Comparing the youth version of the Psychopathy Checklist with the Youth Psychopathic Traits Inventory. Behavioral Sciences \& the Law, 21(6), 737-770.

Lilienfeld, S. O., Latzman, R. D., Watts, A. L., Smith, S. F., \& Dutton, K. (2014). Correlates of psychopathic personality traits in everyday life: Results from a large community survey. Frontiers in Psychology, 5, 740.

Sutherland, M. T., \& Stein, E. A. (2018). Functional neurocircuits and neuroimaging biomarkers of tobacco use disorder. Trends in Molecular Medicine, 24(2), 129-143.

Thomsen, K. R., Osterland, T. B., Hesse, M., \& Ewing, S. W. F. (2018). The intersection between response inhibition and substance use among adolescents. Addictive Behaviors, 78, 228-230.

Vandaele, Y., \& Janak, P. H. (2018). Defining the place of habit in substance use disorders. Progress in Neuro-Psychopharmacology and Biological Psychiatry, $87,22-32$.

Verona, E., Sprague, J., \& Sadeh, N. (2012). Inhibitory control and negative emotional processing in psychopathy and antisocial personality disorder. Journal of Abnormal Psychology, 121(2), 498.

Vitale, J. E., Newman, J. P., Bates, J. E., Goodnight, J., Dodge, K. A., \& Pettit, G. S. (2005). Deficient behavioral inhibition and anomalous selective attention in a community sample of adolescents with psychopathic traits and low-anxiety traits. Journal of Abnormal Child Psychology, 33(4), 461-470. 
Volkow, N. D., \& Li, T. K. (2004). Drug addiction: the neurobiology of behaviour gone awry. Nature Reviews Neuroscience, 5(12), 963-970.

Wechsler, D. (1981). Wechsler adult intelligence scale-revised (WAIS-R). Psychological Corporation.

White, S. F., Frick, P. J., Lawing, K., \& Bauer, D. (2013). Callous-unemotional traits and response to Functional Family Therapy in adolescent offenders. Behavioral sciences \& the Law, 31(2), 271-285.

Wilcox, C. E., Calhoun, V. D., Rachakonda, S., Claus, E. D., Littlewood, R. A., Mickey, J., ... \& Hutchison, K. E. (2017). Functional network connectivity predicts treatment outcome during treatment of nicotine use disorder. Psychiatry Research: Neuroimaging, 265, 45-53.

World Health Organization. (2018). The fatal link between tobacco and cardiovascular diseases in the WHO South-East Asia Region-May 2018. 